\title{
Los tormentos de un maestro Entrevista a Hans-Georg Gadamer
}

Por Antonio Gnoli y Franco Volpi

La entrevista que presentamos a continuación forma parte del libro L'Ultimo Sciamano. Conversazioni su Heidegger (Milano: Tascabili Bompiani 2006, 135 pp.). La Casa Editorial Los Libros de Homero publicó en noviembre de 2008 una primera traducción no comercial de esta compilación de entrevistas realizadas por el filósofo Franco Volpi y el periodista Antonio Gnoli a aquellos que conocieron y convivieron de cerca con Martin Heidegger - Hermann Heidegger, Ernst Jünger, Hans-Georg Gadamer, Ernst Nolte y Armin Mohler - con el título El último chamán. Conversaciones sobre Heidegger. La edición al público será publicada en 2009. La traducción fue realizada por Jesús Salazar Velasco.

En unos apuntes inéditos fechados el 22 de enero de 1939, Heidegger anota que Gadamer es «el único que domina verdaderamente la filosofía antigua, la cual es y permanece como el alfa y el omega de la educación filosófica». Probablemente esta es la razón de la sintonía filosófica entre los dos, la cual se mantuvo inalterada a través de los sobresaltos del siglo: la convicción común sobre la importancia fundamental de los griegos para la civilización occidental. Así pues, Gadamer fue, desde el punto de vista filosófico, el alumno predilecto de Heidegger. Fuimos a visitarlo a Ziegelhausen, el suburbio de Heidelberg donde vive. La cita es a primera hora de la tarde. La lluvia, el silencio y el verde abrazan esta pequeña colina residencial desde la que es posible divisar el río Neckar que ciñe la ciudad, sede de una prestigiosa universidad.

Gadamer nos recibe a la puerta de su casa. La figura imponente se sostiene en dos bastones que las manos del filósofo estrangulan: «Como ven, las piernas no me sostienen más, ya me fatiga viajar. Pero todavía puedo recibir invitados y trabajar muy bien».

Con cierta fatiga Gadamer nos guía en la estancia donde nor- 
malmente trabaja. Entre los libros, cartas y apuntes, mezclados en un placentero desorden, acampa una botella de Montepulciano, que el filósofo, ya sentado en su sillón, destapa con alegría. «Adoro los vinos italianos - comenta - , recuerdo que en la boda de Vittorio Mathieu, una ceremonia suntuosa, bebimos un barolo extraordinario». Dentro de unos meses cumplirá cien años ${ }^{1}$. Es la ocasión para un brindis anticipado.

Profesor Gadamer, usted nació en 1900, al alba de un siglo del cual asistimos al final y que usted, como otros pocos, ha atravesado por entero. Su camino intelectual se entrelaza con la historia de la cultura alemana y europea del siglo veinte. El amplio recuento de su vida que ha publicado Jean Grondin a tiempo para el centenario ${ }^{2}$ es en efecto una muestra de la filosofía de nuestro siglo.

Un trabajo preciso y bien documentado, pero con todo respeto, lleno de indiscreciones que habría preferido no ver publicadas. ¡Ay de mí!, yo mismo he cometido la imprudencia de contárselas.

Usted ha estado lado a lado con todos los grandes personajes del pensamiento alemán de este siglo: Husserl, Scheler, Natorp, Hartmann, Heidegger y tantos otros. El elenco es impresionante. Luego, con la hermenéutica, ha influenciado profundamente la filosofía mundial de los últimos decenios. ¿Cómo ocurrió su entrada a la filosofía?

Que la filosofía fuera mi camino lo supe relativamente tarde, en Marburgo. Durante mis años de juventud, que transcurrieron por entero en Breslavia, donde mi padre trabajaba como químico en el campo farmacéutico, me gustaba sobretodo la literatura: Shakespeare, los clásicos griegos y alemanes, en particular la lírica, pero no había leído aún ni a Schopenhauer ni a Nietzsche, dos autores casi de culto en la época, aunque rechazados por la filosofía universitaria.

2 Ver Jean GRONDIN, Hans-Georg Gadamer. Una biografía, Barcelona: Barcelona 2000. 
También Edith Stein era de Breslavia, ¿la conoció?

No, personalmente no nos encontramos jamás. Pero mi mujer la conocía bien, habían asistido a la misma escuela. Yo llegué a Friburgo, donde ella se hizo asistente de Husserl, en el semestre de verano de 1923 únicamente para escuchar a Heidegger.

¿Qué recuerda en particular de aquellos primeros años del siglo?

El acontecimiento que más me impresionó, en buena medida porque recuerdo todavía las largas conversaciones a la mesa con mi padre, fue el hundimiento del Titanic. Para comprender cabalmente qué había significado aquella catástrofe sería necesario tener mi edad. Recuerdo que era el tema del día, todos hablábamos, incluso en círculos intelectuales se discutía para interpretarlo. Era la primera señal, el primer síntoma de que el progreso no traería solamente rosas sino también espinas y dolores. Era el inicio de un escepticismo que minó la fe incondicionada que todavía se nutría en la discusión sobre la ciencia y la técnica. Una fe que en Alemania se combinaba con el espíritu prusiano y sus virtudes típicas: el orden, el trabajo, la organización, la disciplina. Comenzó a abrirse una grieta no solamente en el optimismo típico de la era del positivismo, sino también en la visión del mundo sobre la cual se había construido mi educación. Comenzó el distanciamiento del ambiente de mi hogar.

¿Qué experiencias culturales maduraron este distanciamiento?

Se presentó frente a mis ojos el libro Europa y Asia de Theodor Lessing, un outsider singular, que desarrollaba una crítica de la civilización occidental. Otra visión alternativa del mundo para mí fue también aquella proyectada por Stefan George y su círculo. Fue una experiencia decisiva para mi formación. Y luego las Consideraciones de un impolítico de Thomas Mann, un libro grandioso y extraordinario para mí. Comencé a comprender y apreciar entonces la importancia de los valores espirituales de la Kultur humanística respecto de aquellos materiales de la moderna Zivilisation. En aquellos años mi padre fue transferido a Marburgo, donde tomé decididamente el camino de la filosofía, influenciado al principio por el neokantismo, especialmente los de Paul Natorp y Nicolai 
Hartmann, que enseñaban allí. Aprendí mucho también del helenista Paul Friedländer y de Robert Curtius. Y luego las enseñanzas inolvidables del teólogo Bultmann, de quien me hice amigo. Pero sobre todo fue decisivo para mí el encuentro con Heidegger, por todo lo que aprendí con él. Entre nosotros, sus alumnos más viejos, especialmente Löwith, Gerhard Krüger y yo, se formó una unión inolvidable.

\section{¿Qué impresión le dejó Heidegger?}

En el verano de 1923 fui a Friburgo a escuchar sus lecciones. Nuestros compañeros de Marburgo que iban a escucharlo regresaban encantados por la magia de sus clases. Contaban acerca de un modo completamente nuevo de hacer hablar a los textos de la tradición. También yo quedé impresionado. Escucharlo interpretar a los griegos, Platón, Aristóteles, y luego a Pablo, Agustín, el joven Lutero, verlo en el trabajo de sus primeras tentativas de encontrar un vocabulario filosófico nuevo para acoger el sentido de la existencia humana, era verdaderamente una experiencia indescriptible. Casi como asistir a un espectáculo de la naturaleza. En el aire había la sensación de que un nuevo astro estaba naciendo en el firmamento de la filosofía alemana.

\section{¿Cómo se portó con usted?}

Al inicio, cuando seguí por primera vez sus cursos en 1923, tuve con él una relación estrictamente académica, de alumno y maestro. La relación se hizo más profunda sobre todo por el tiempo en que estudiamos a Aristóteles. Cuando vino a Marburgo se desarrolló una relación mucho más intensa, puedo decir que confidencial y casi familiar. Fue, entre otras cosas, padrino de bautizo de mi hija.

Revisando la lista de los participantes a los seminarios de Heidegger de aquellos años, se encuentran muchos nombres que han marcado la filosofía alemana contemporánea...

Es cierto, en Friburgo estaban Walter Bröcker, Joachim Ritter, Hans Jonas, Horkheimer. Más tarde llegó de Berlín también Marcuse, que ya era famoso: se hizo colaborador de Heidegger y escribió bajo su guía su tesis de habilitación para la docencia universitaria. 
Una vez vino a escucharlo también Leo Strauss, pero sólo de paso. Recuerdo que Heidegger estaba comentando el primer libro de la Metafísica de Aristóteles, y también para Strauss, que había estudiado en la mítica Heidelberg de Max Weber, fue una impresión inolvidable, tanto que cuando en 1933 nos reencontramos en París, evocamos con profunda nostalgia aquella experiencia. Strauss decía que en comparación con la profundidad y el rigor exegético de Heidegger, Max Weber le parecía un «pobre huerfanito». Por no hablar del célebre aristotélico Werner Jaeger. Strauss tuvo oportunidad de escucharlo en Berlín mientras interpretaba los mismos pasajes interpretados por Heidegger: era mejor, decía, limitar la comparación diciendo que no había comparación. En suma, Heidegger era simplemente fenomenal en clase: daba rienda suelta a su extraordinaria imaginación filosófica y su inalcanzable capacidad para adentrarse en los textos. No he visto nunca más un talento filosófico parecido al suyo.

Sin embargo, personajes como Weber o un movimiento como el Círculo de Stefan George, ¿tuvieron una cierta influencia sobre Heidegger?

Seguramente, y más profunda de cuanto se pueda suponer. Precisamente la influencia del Círculo de George me acercaba a él. Heidegger estaba interesado en él en sus años de juventud, antes de que nos encontrásemos. Desde el momento en que también yo era un apasionado de la poesía de George, cuando nos conocimos esta experiencia común nos puso en sintonía y nos unió intelectualmente. Lo mismo vale para Max Weber. Heidegger había seguido con atención su presencia, lo valoraba con gran respeto y admiración, aunque veía en él al hombre de mundo, la figura pública, lejana de aquel ambiente cotidiano que él amaba. En cuanto al punto de vista filosófico que estaba entonces elaborando, era claro que aquello acentuaba también las diferencias. Pero lo consideraba interesante y más profundo que Rickert, de quien, por otro lado, Weber había tomado prestadas buena parte de sus categorías filosóficas.

¿Qué otra cosa fue determinante para su maduración filosófica?

Tuvo gran importancia también su distanciamiento del catolicismo, en el cual había crecido, y la confrontación en todos los campos 
con la experiencia religiosa después de «la muerte de Dios». Puedo decir que los años de Marburgo, entre 1923 y 1928, en los cuales lo frecuenté más intensamente, estuvieron marcados por este proceso de alejamiento. Fue importantísima su relación con Bultmann, con quien trabó una amistad muy profunda, la cual duró toda la vida, y que ni siquiera la catástrofe del nacionalsocialismo hizo vacilar.

Uno de los motivos centrales del pensamiento de Heidegger es la crítica a la técnica moderna. ¿Cómo es esto? ¿Puede ser que Heidegger se haya impresionado en la juventud por el naufragio del Titanic, y que en aquella impresión se encontraran las raíces lejanas de su crítica al mundo técnico?

No, creo que el evento del Titanic interesó solo marginalmente el mundo campesino en el cual Heidegger se había formado y en cual permaneció arraigado. En Meskirch, cuando Heidegger vivió su primera juventud, probablemente la técnica moderna no había llegado aún. Solamente más tarde comenzó a interesarse por el problema, como atestiguan sus escritos. Todavía en Ser y tiempo casi no se habla de aquello.

Se dice que aquello que le abrió los ojos sobre la transformación técnica del mundo fue la lectura de El trabajador de Ernst Jünger. Quizá también Max Scheler, que era un hombre enteramente penetrado en la vida moderna de la ciudad.

Creo que, más que Jünger o Scheler, fue simplemente un proceso de evolución personal. Viniendo de un ambiente campirano, Heidegger no había tenido mucho contacto con la vida urbana moderna. Solo más tarde, en Friburgo y Marburgo, y con la fama mundial que le procuró Ser y tiempo y los viajes que hizo por toda Alemania dando conferencias, tuvo contacto con la complejidad del siglo.

Fue durante uno de estos viajes que conoció a Scheler.

Como naturaleza filosófica Scheler le era muy familiar, y tuvo mucha influencia sobre él. Heidegger mismo, después de haberlo conocido en persona, lo admitía abiertamente. Pero en aquella época, cuando hablaba con nosotros, era casi siempre muy severo al discutir la antropología filosófica scheleriana. 
En aquellos años, o poco después, Heidegger descubrió a Nietzsche.

A través del expresionismo y de las vanguardias artísticas y literarias Nietzsche estaba presente en la cultura alemana desde el inicio del siglo. También el joven Heidegger respiró aquella atmósfera. Pero comenzó a enfrentar seriamente los textos nietzscheanos más tarde, hacia la mitad de los años treinta. Se había publicado ya el libro de Jaspers sobre Nietzsche, y Heidegger estaba unido a él por una profunda amistad. Aun antes se había publicado el libro de Alfred Baeumler, de quien también Heidegger era amigo. La importancia del fenómeno Nietzsche para el alma alemana era clara para todos, y también Heidegger quiso interpretarla. En verdad, no sé si lo haya logrado. Su hijo Hermann me ha contado que Nietzsche marcó en la vida de su padre una crisis profunda y que en casa solía repetir: «¡Nietzsche me ha destruido!». Cierto es que la interpretación que elaboró es una pieza de valor incomparable.

No sabíamos que Heidegger era amigo de Baeumler.

Sí, hasta cierto punto. Por lo demás Baeumler no era para nada tonto, escribió un libro nada malo sobre la Crítica del juicio de Kant. Heidegger, sin embargo, había criticado severamente sus interpretaciones de Nietzsche. Baeumler, que con Ernst Krieck y Alfred Rosenberg se había convertido en aquellos tiempos en uno de los inspiradores de la política cultural del partido nacionalsocialista, lo obstaculizó de todas las formas posibles. Por lo mismo se hizo también un acérrimo enemigo mío e intentó por todos los medios bloquear mi carrera.

\section{Hablábamos de Nietzsche...}

En aquellos años en el mundo alemán era casi obligatorio enfrentarse con él. No había un filósofo, literato o artista que no tuviese en su biografía una frase nietzscheana. Yo me encuentro entre los pocos que no se enamoraron nunca de Nietzsche.

Usted prefería sin embargo el Nietzsche de los literatos que el de los filósofos.

Admiraba sobre todo algunos poemas de Nietzsche. Naturalmente me doy cuenta que mi fallida relación con Nietzsche es de cualquier modo también un límite. 
Entre los grandes lectores de Nietzsche se encuentra Ernst Jünger, ¿lo conoció?

Conocí a Ernst y a su hermano Friedrich Georg. Eran dos personalidades completamente diferentes. Ernst era más genial, se sabe, pero tenía también un carácter más difícil. Por otro lado Friedrich Georg era un poeta, un romántico, muy abierto. Durante cierto tiempo nos frecuentamos. Algunas veces fui a visitarlo al lago Constanza, donde vivía con su mujer. Aprecio en particular lo que ha escrito sobre la técnica. Su libro La perfección de la técnica, para el cual se inspira en la concepción heideggeriana, es en cierto sentido el correspondiente a El trabajador de su hermano. De este último recuerdo en particular un encuentro, con ocasión de una conferencia de Heidegger en Suiza, en la que también él se encontraba presente. Sin embargo me dejó la impresión de un hombre con la típica formación militar: porte rígido, voz casi metálica, átona.

Heidegger, Baeumler, Jünger... nombres que evocan los tiempos del nacionalsocialismo. Según usted, ipor qué razones en 1933 Heidegger entró en el partido nacionalsocialista y se hizo elegir rector de la Universidad de Friburgo?

Cuando nos llegó la noticia a Marburgo de que había tomado postura a favor del nazismo, ninguno de nosotros podía creerlo. ¿Heidegger nazi? «iImposible!». fue nuestra primera reacción. Ciertamente, porque lo conocíamos muy bien. El hecho de que en 1933 había aceptado el puesto de rector es simplemente un absurdo, un contrasentido. Su esperanza de promover un renacimiento de la universidad cabalgando en el movimiento nacionalsocialista fue una ingenuidad increíble, tanto más para alguien como él, carente de cualquier noción acerca de qué cosa es y cómo funciona un aparato burocrático. Recuerdo que cuando tomó el cargo, pocas semanas después toda la administración universitaria estaba paralizada porque, escrupuloso como era, pretendía ver y controlar personalmente todo documento que firmaba. Y si primero no había leído todo, no firmaba. ¡Típico de Heidegger! 
Löwith escribe cosas terribles sobre su comportamiento después de 1933...

En realidad tiempo atrás se había comprendido que la situación estaba empeorando y estaba en camino de una caída fatal. Era claro que para Löwith, de origen judío, no había ninguna posibilidad de permanecer en la universidad alemana. Heidegger hizo todo lo que pudo por ayudarlo. Pero no tenía un corazón de león ni habría podido obtener nada de los nazis. El destino de Löwith estaba marcado desde el principio.

¿Qué fue lo que provocó la ruptura entre los dos?

Löwith estaba en Roma gracias a una beca. Heidegger fue enviado en 1936 a una conferencia. El día siguiente fue a visitar a su ex alumno a casa. Se presentó rígido, casi exhibiendo el distintivo del partido que portaba en el ojal. No pensó cuando menos en quitárselo o esconderlo. Löwith consideró que esa absoluta carencia de sensibilidad era ni más ni menos que una provocación. Y fue el inicio de la ruptura.

Usted, que era amigo de los dos, ¿cómo juzgó el episodio y cómo se comportó?

Mi caso era obviamente distinto. También yo fui culpado por la salida de Heidegger, pero reaccioné en modo opuesto a Löwith: lo consideré una incapacidad del hombre Heidegger para enfrentar con valentía la situación.

\section{¿Mantuvo contacto con Löwith?}

Después de la Primera Guerra Mundial y después de la crisis de 1929 para nosotros se hizo casi imposible viajar. Por eso el único contacto que mantuve fue epistolar. A decir verdad, era sobre todo mi mujer quien le escribía, intercambiando largas cartas en las cuales nos contaba de su vida en Italia. Cuando lo volví a ver, obviamente hablamos de Heidegger, y él mismo me contó el encuentro en Roma. Fue el comienzo de su distanciamiento del maestro y amigo de algún tiempo. Una herida que no cicatrizó del todo jamás. 
Entre ellos había una intensa relación personal.

Es verdad, tanto que la relación no era la que habitualmente existe entre un maestro y un alumno. Era más que eso. Entre ellos había una familiaridad, casi diría intimidad. En Friburgo, en los años inmediatos a la Primera Guerra Mundial, Heidegger, Löwith y Osta Becker (que era asistente de Husserl al mismo tiempo que Heidegger) formaban una especie de trío. Pienso que la amistad de Heidegger con Löwith podría ser comparada por su intensidad con la de Jaspers. Aquello que los unía era la oposición al academicismo de la filosofía de la época. Especialmente Heidegger, que era de origen humilde y venía del mundo del campo, aborrecía el formalismo en el comportamiento de los académicos y todo aquello que implicaba compromisos. Las inevitables precauciones diplomáticas, necesarias en la convivencia universitaria, estaban, para él, empapadas de falta de autenticidad, falsedad. Respecto a esta intransigencia moral, que mantuvo con rigor de inicio a fin, el hecho de que en 1933 haya aceptado el cargo de rector - vuelvo a decirlo - es simplemente una incongruencia incomprensible para mí.

Se ha dicho que Heidegger era antisemita.

Ciertamente Heidegger tenía un carácter medroso, pero decir que era antisemita es una tontería. Paul Friedländer, un helenista de origen judío que enseñaba filosofía clásica en Marburgo y había colaborado con Heidegger y organizado con él algunos seminarios, cuando por casualidad tocaba este punto decía que para Heidegger el único criterio de selección era la inteligencia, no el ser judío o ario. Del resto, el hecho de que tenía numerosos alumnos judíos es la mejor refutación de esas habladurías: además de Löwith, Jonas, Günther Anders, Hannah Arendt, Marcuse. Además, es cierto que al inicio de los años treinta su asistente era judío, un cierto Werner Brock, a quien ayudó a emigrar al Reino Unido.

Pero la poesía que Celan escribió después de su visita a la cabaña de Todtnauberg alude al hecho de que sobre este punto Heidegger se mantenía evasivo.

No creo que la poesía de Celan quiera decir eso. Por lo demás, encuentro reductiva la interpretación de su relación en estos tér- 
minos, como si no hubiese habido otro tema de conversación que el nacionalsocialismo y el holocausto. Su diálogo seguramente fue mucho más allá. Estaban interesados el uno por el otro. Heidegger era un apasionado de la poesía de Celan, y la admiraba como un gran arte, como una forma del pensamiento poético que él deseaba. A su vez, Celan estaba interesado en los motivos filosóficos que Heidegger trataba. La atracción que tenían el uno por el otro hundía sus raíces en un común sentir acerca de la importancia de la poesía en un tiempo de crisis como el nuestro.

Parecería una ulterior confirmación de la infundada acusación de antisemitismo.

La prueba más elocuente de ello es su extraordinaria historia de amor con Hannah Arendt.

Entonces, ¿había algo manifiesto sobre la relación entre ambos?

Nada, absolutamente nada. También para nosotros fue una sorpresa, que arroja una luz positiva sobre su personalidad, que nos revela su humanidad. Y también la mujer de Heidegger resulta revalorada. Solamente se conoce de ella la imagen de una nazi fanática. Pero las cosas no son simplemente así. El hecho de que Heidegger decidiera permanecer con ella no se debió solamente a la inercia de las cosas, a la debilidad de carácter y al miedo, sino que significa en algún modo lo que Elfride hacía por él. Significa que el trabajo doméstico que ella organizaba les permitía ser lo que eran. Heidegger poseía una imaginación ilimitada e impredecible, pero al mismo tiempo una disciplina laboral de hierro, y aunque se expuso al riesgo de perderse y pronto tenía muchas tentaciones, especialmente con el otro sexo, alcanzó verdaderamente a realizar una obra filosófica de rara grandiosidad.

¿Qué trata de decir cuando alude a las relaciones de Heidegger con el otro sexo?

Que Hannah Arendt fue solo el inicio. Evidentemente ella le había hecho descubrir los placeres de la carne, lo había hecho feliz, y su historia permaneció para Heidegger como única e irrepetible. Por cuanto pueda parecer increíble, él, con su personalidad caris- 
mática, ejercía sobre las mujeres una fascinación y atracción especiales. Después de la historia con Arendt probablemente no haya opuesto resistencia a su inclinación y se dejó llevar a otras aventuras. Circulan muchas anécdotas, en parte también verdaderas, pero en estas cosas la discreción es una obligación para mí.

En cuanto a su esposa, ¿se puede decir que influyó sobre su inicial adhesión al nazismo?

También ésta es una historia contada muy a menudo, pero muy poco dimensionada. Su mujer era hija de un oficial prusiano, y ciertamente simpatizó con el nuevo movimiento que alentaba el sentimiento de frustración muy difundido entre los alemanes y que alimentaba el nacionalsocialismo y el revanchismo. Pero fueron otras las motivaciones y ambiciones las que incitaron a Heidegger a hacerse elegir rector.

De cualquier modo, se dice que Elfride era particularmente rígida. Se cuenta que detuvo a su marido para no ir a los funerales de Husserl.

También este episodio revela la debilidad de Heidegger. Fue una falta de valor imperdonable. Estábamos ya en 1938, y probablemente temía que su participación lo hubiese comprometido a los ojos de los nazis. Ciertamente él no tenía ninguna posibilidad de incidir activamente en las decisiones concernientes a la política cultural nacionalista, como quizá había esperado cuando aceptó ser rector.

¿Cómo vivió Heidegger los años posteriores a la guerra?

Había perdido todo. Desde cualquier punto de vista, material y espiritual, atravesó una crisis profunda. El drama era que ya antes de la guerra había tomado distancia del entusiasmo inicial por el nazismo, que criticaba en sus lecciones, como otros. Pero, temeroso como era de carácter, no tenía el valor para manifestar abiertamente su desacuerdo, y al final de la guerra se le quiso hacer pasar por el nazi que no era.

¿Usted fue uno de los que contribuyeron a su rehabilitación?

Sí, yo tomé la iniciativa. Lo sentía como un acto obligado para 
con un hombre que tanto había dado, a nosotros y a la filosofía, y que se encontraba en una condición de postración indigna. Me irritaban los ataques estúpidos que padecía, muy frecuentemente hipócritas y mezquinos. Era un absurdo impedir al más grande filósofo vivo que enseñara y trabajara. Busqué romper el ostracismo que algunos quisieron imponer sobre su obra. Puesto que había sido nazi, pensaban, tendremos que prohibir leerlo. Me parecía una estupidez que necesitaba desbaratar. Organicé, con mil dificultades, un volumen en su honor en el que contribuyeron nombres ilustres de la intelligencija alemana: Ernst Jünger con el ensayo Sobre la línea, su hermano Friedrich Georg, Romano Guardini, Walter F. Otto, Karl Löwith, Gerhard Krüger y otros más. Más tarde logré hacerlo elegir en la Academia de Heidelberg. Pero fue toda una empresa, y llegó a buen fin sólo con el apoyo determinante de Löwith. Heidegger nos lo reconoció.

A propósito de Löwith, ¿por qué cuando fue obligado a emigrar se decidió por Japón y no, por ejemplo, por Estados Unidos?

Fue una salida casi obligada, que no dependía de sus preferencias culturales. Luego de haber sido despedido, y no sin reservas, pidió ayuda a Heidegger, que tenía contactos con el mundo japonés y le escribió algunas cartas de recomendación. Así fue como Löwith terminó de esta manera, en cierto sentido casual, en el extremo Oriente. Por otro lado, no fue el único que recibió apoyo. Heidegger ayudó a otros de sus alumnos judíos. Werner Brock, como he dicho, después Helene Weiss, una tía de Ernst Tugendhat, que recomendó al aristotélico W. Ross en Oxford. Al inicio del régimen, el hecho de que un profesor ordinario ayudase a sus propios alumnos en apuros era algo todavía común, y en el conjunto bastante practicada.

Usted muestra en el análisis de Heidegger una gran humanidad, pero en la filosofía ha tomado gran distancia de él.

En aquel entonces percibí la peligrosidad de su decisión. Mi reacción fue evitar cualquier contacto con él, y por cinco años no lo volví a ver. No por razones morales, o porque quisiera manifestarle mi desacuerdo. Simplemente no quería ser comprometido. No que- 
ría estar cerca, y pensaba que una recomendación suya proveniente del partido o de la autoridad nacionalsocialista me habría sido más bien de daño que de ayuda.

Quizá el único verdadero acto de valentía de Heidegger fue su dimisión como rector. Fue una auténtica provocación el desacuerdo con las jerarquías nacionalsocialistas. Pero el público no entendió el significado de este gesto. Y para él entonces comenzaron las dificultades. Para quien tenía oídos, su toma de distancia del nacionalsocialismo fue completa y clara.

¿Es verdad que cayó en una crisis profunda, también psíquica?

En aquel momento yo estaba en Marburgo, donde enseñaba con Gerhard Krüger. Nos llegaban noticias de cuanto acontecía en Friburgo, y naturalmente también de Heidegger, pero sólo de manera indirecta e intermitente. De cualquier manera, circulaba la voz de que Heidegger se encontraba en una crisis grave. Había estado gravemente enfermo de ictericia y había caído en una profunda depresión. Le tomó un año recuperarse.

\section{¿También conoció a Carl Schmitt?}

Así es, pero no tuve una relación fácil con él. Para mí, protestante, el mundo de sus pensamientos me parecía lejano, extraño. Leí ávido, tan pronto salió, su libro sobre el romanticismo político, en particular la parte dedicada a Schlegel me impresionó. Quizá es verdad que no sólo fue un jurista, sino también un teólogo político. Sin la radicalidad de su visión católica de la historia no se comprenden sus conceptos.

¿Y en el plano personal?

A veces asumía una actitud de superioridad que me resultaba fastidiosa. Recuerdo que cuando estaba en Leipzig, durante la guerra, venía frecuentemente a nuestra ciudad donde residían muchos de sus alumnos. Formalmente, su comportamiento era muy gentil, pero el desdén con que nos trataba, como si fuésemos todos ingenuos, era irritante, casi ofensivo. 


\section{A su parecer, ¿se puede decir que fue un grande?}

Ciertamente, era una gran pensador, un enorme jurista, infinitamente superior a todos los juristas de su época. Y por ello le divertía discutir de modo sofístico, jugar con sus interlocutores como el gato con el ratón. Le gustaba recitar, escenificar una disputa.

\section{¿En qué sentido?}

Recuerdo por ejemplo una ocasión, durante una visita a Lepzig, en la que discutió un caso ficticio: si un hombre político que ha cometido un crimen común debe ser sometido a la justicia ordinaria. Carl Schmitt se divertía defendiendo con sobrada habilidad la posición del acusado, sosteniendo que aquel crimen debía ser considerado como una debilidad irrelevante comparada con la importancia del político, el cual debería ser tratado aparte al orden de los comunes mortales: hace las leyes y está por encima de ellas; debe permanecer libre. Carl Schmitt defendía esta tesis, absurda e inaceptable para todos nosotros, con una habilidad mefistofélica. Lo que me ponía furibundo era que en realidad no podíamos refutarlo, aunque fuera evidente que había pasado el límite. Después supe que entonces, como en otras ocasiones, para él se trataba de un juego de habilidad erística, en el que se empeñaba solo por el gusto de la paradoja.

¿Se puede decir que fue uno de los últimos herederos del gran pensamiento político renacentista, el último de los maquiavélicos?

Quizá, aunque para mí como protestante, repito, su interpretación del orden político resulta difícil de comprender e imposible de compartir.

¿Quizá porque su hermenéutica se encuentra en las antípodas del decisionismo schmittiano?

También por eso. Pero creo que su decisionismo, sobre el cual tanto se ha discutido, era solamente una máscara detrás de la cual se escondía. Un juego irónico con el cual se burlaba de los politólogos contemporáneos. Consideraba a todos los intelectuales, filósofos incluidos, juguetones ingenuos que cambiaban sus diatribas por la dialéctica real del mundo, por la historia universal, 
cuyo sentido le preocupaba profundamente. Quizá era demasiado inteligente para nosotros.

¿Pero verdaderamente era un juego irónico el de Schmitt?

Estoy convencido que si no se toma esto en cuenta es imposible entrar en el corazón de su pensamiento, que era un concentrado de religiosidad y de agudeza intelectual, al fondo del cual estaba la inaudita convicción de ser el auténtico intérprete del orden católico de la historia universal.

Era amigo de Kojève, quien acuñó el concepto de «hermenéutica de la reticencia»...

Conocí también a Kojève, en 1933 en París. También Kojève tenía el mismo gusto por la paradoja de Carl Schmitt, y también él se divertía recitando su parte, jugando su juego.

\section{¿Y Leo Strauss?}

No, su caso es del todo distinto. Era un moralista. Lo conocí muy bien y puedo decir que su disgusto era en verdad la fractura entre la filosofía y la política que atraviesa el pensamiento contemporáneo, y que él veía personalizada en Heidegger y su nihilismo. De ahí su relación ambigua con él: estaba profundamente impresionado por su genio filosófico, pero detestaba su falta de sentido político.

Y su idea de que un texto debe ser leído poniendo más atención en aquello que no dice que en aquello que dice, esta forma de mimetismo con el autor, en el fondo es próxima a la hermenéutica.

En la hermenéutica de la reticencia es así, pero no se pueden poner al revés los términos de la comprensión. Nadia hablaría y diría tanto si aquello que dijese fuese falso. Por otra parte, la palabra proferida siempre está expuesta al malentendido. Es necesario hacer precisiones y matices de manera continua para evitar el malentendido o corregirlo. 
Otro personaje que despierta la curiosidad y que fue muy cercano a Carl Schmitt fue Walter Benjamin...

Ah, ¡Walter Benjamin! Se podría especular sobre lo que hubiera sido de él, y aquello en lo que se habría convertido si no se hubiese suicidado.

¿Qué quiere decir?

Que era una personalidad rica, explosiva, genial, que se habría podido convertir en todo lo contrario que fue. Tenía una genialidad verdaderamente fuera de lo común, impredecible. Era del calibre de Carl Schmitt, o de Heidegger. Pero Carl Schmitt tenía algo de diabólico que ni Heidegger ni Benjamin tenían.

Usted ha desarrollado un gran papel en el pensamiento alemán de la postguerra. Ha mediado entre la escuela heideggeriana y la Escuela de Francfort. Luego, con la hermenéutica filosófica, ha construido un puente entre la discusión filosófica europea y la americana.

La mediación más difícil y delicada fue con la Escuela de Francfort, especialmente con Adorno. Yo había mantenido, en el plano filosófico, una cierta distancia e independencia de Heidegger. Me había cuidado de hacer una repetición idéntica de sus tesis, de la asimilación pasiva de su vocabulario, había evitado seguirlo en sus malabarismos especulativos. En su lugar he recuperado algunos problemas que originalmente él había identificado y desentrañado con una fuerza de penetración inigualable. Fueron mis raíces humanistas las que me permitieron balancear la radicalidad heideggeriana y me enseñaron a tener una relación menos radical con el mundo.

Usted ha «urbanizado la provincia heideggeriana», como ha dicho Habermas.

Con esa expresión Habermas intentaba hacerme un cumplido y hacer una crítica a Heidegger. En realidad, también ha señalado la debilidad de mi pensamiento respecto de la fuerza del pensamiento heideggeriano. 
¿Y Habermas?

Con él he construido a través del tiempo una relación amistosa, aun cuando nuestras concepciones filosóficas y políticas hayan sido muy diferentes. Al comienzo lo apoyamos en su carrera, que los viejos francfortenses, Adorno y Horkheimer, no favorecieron mucho. Hizo falta que venciera también la resistencia de Löwith, que le era contrario. Yo decía que necesitábamos uno como él, que pensaba diferente de nosotros, pero que estaba dispuesto al diálogo, cosa que con Adorno algunas veces era bastante difícil.

\section{¿También conoció a Marcuse?}

Ciertamente, y puedo decir que su franqueza rozaba la ingenuidad. Y quizá fuera lo que yo apreciaba aun más de entre los francfortenses. Era llevadero, abierto, comprensivo. Con él era posible discutir y dialogar con mucho provecho. No tenía la facciosidad e intransigencia típicas de Adorno.

Usted era considerado una eminencia oculta del conservadurismo, ¿cómo veía aquellos años de protesta estudiantil?

A diferencia de muchos otros académicos, que tenían infinitos problemas y que entraron en crisis junto al modelo de universidad que representaban, yo no tuve ninguna dificultad con los estudiantes y salí indemne de aquella etapa. Por lo demás, se trataba de mediar y comprender las exigencias de renovación inmersas en las protestas juveniles, no de oponer un comportamiento reaccionario.

Usted ha atravesado por entero este siglo, que ha sido un siglo de contradicciones, anomalías y paradojas. ¿Cuál es su balance personal?

Diría que los totalitarismos, diferentes y sin embargo iguales, han sido uno de los fenómenos funestos que marcaron el siglo veinte. He vivido la situación como un trágico dilema sin salvación en el que nos hemos encontrado bajo el régimen nacionalsocialista. Consideré siempre mi deber moral hacer saber a mis alumnos que estaba en contra de Hitler. Pero cuando Hitler declaró la guerra a Stalin, era difícil hacer entender que estaba al mismo tiempo también contra Stalin. Un dilema existencial ante el cual no se sabía 
qué hacer. Algunos de mis alumnos, Walter Schulz por ejemplo, vivieron aquello como una verdadera y completa crisis.

¿Qué piensa del análisis de los totalitarismos elaborado por dos estudiosos diferentes como Hannah Arendt y Ernst Nolte, ambos, aunque en periodos diversos, alumnos de Heidegger?

Ambos tienen razón parcialmente. Pero si debiera confrontar sus doctrinas políticas con aquellas de Carl Schmitt, puedo decir que son dos buenos jóvenes, en el sentido en que creen todo aquello que dicen.

\section{¿Cuál es su relación con la política?}

He escrito un ensayo sobre la ineptitud política de los filósofos. No se cuál será nuestro destino. Como decía, la mayor dificultad es encontrar un orden político a la altura del mundo organizado según los imperativos de la técnica, es decir, el mundo globalizado. En una pregunta: ¿qué sistema político podrá contener el sistema de la técnica? ¿Quizá la democracia? Soy muy escéptico al respecto. No quiero hacer previsiones catastróficas, no me gusta el tono apocalíptico. Pero no es difícil imaginar lo contrario, la técnica que se impone a la política: un orden mundial parecido a un Estadohormiguero en el que los ojos vigilantes de los aparatos controlarán aquello que cada individuo singular hace o no hace. Es un escenario no improbable en un futuro no demasiado lejano. Aún podemos soñar que al final alguna potencia nos salvará. Quizá esa potencia sea Dios.

Una última curiosidad: con la cultura italiana usted ha tenido una relación especial, ¿podría contarnos cómo nació?

Fue gracias a Löwith, amigo mío y compañero en la escuela de Heidegger. Fue él quien, con su insistencia, me convenció de ir a los cursos del lector de italiano en Marburgo, un cierto doctor Turazza, a quien tuve ocasión de volver a ver, años más tarde, al visitar una muestra de Morandi en Bologna. Aquellas lecciones de lengua y literatura italiana fueron mi primer acercamiento y me dieron una gran motivación. Después, gracias al estrecho contacto con Löwith, era imposible no ser contagiado de su pasión por 
Italia. Había combatido en la Primera Guerra Mundial en el frente italiano, y había caído prisionero, más o menos por los años en los que Wittgenstein sufrió el mismo destino. Löwith se enamoró de Italia durante el cautiverio. Él, que en sus estudios y en el trabajo era un tipo teutónico muy riguroso y meticuloso, en la vida era todo lo opuesto y adoraba todo lo mediterráneo. Recuerdo que su escritorio estaba siempre en orden, y cada vez que tomaba un libro del librero para buscar una cita lo regresaba de inmediato a su lugar. Tenía una necesidad casi obsesiva de escribir y anotar todo con precisión. Exactamente contrario a mí: yo era caótico, desordenado, indisciplinado en el trabajo y en el estudio. Pero fue él quien me transmitió el sentido de humanidad típico de los italianos. 